\title{
Transdiaphragmatic intercostal hernia: imaging aspects in three cases*
}

Hérnia intercostal transdiafragmática: aspectos de imagem em três casos

\section{Ana Carolina Sandoval Macedo, Fernando Uliana Kay, Ricardo Mingarini Terra, José Ribas Milanez de Campos, André Galante Alencar Aranha, Marcelo Buarque de Gusmão Funari}

\begin{abstract}
Transdiaphragmatic intercostal hernia is uncommon and mostly related to blunt or penetrating trauma. We report three similar cases of cough-induced transdiaphragmatic intercostal hernia, highlighting the anatomic findings obtained with different imaging modalities (radiography, ultrasonography, CT, and magnetic resonance) in each of the cases.
\end{abstract}

Keywords: Hernia, diaphragmatic; Radiography; Ultrasonography; Tomography; Magnetic resonance imaging.

\section{Resumo}

Hérnias intercostais transdiafragmáticas são eventos raros e são geralmente relacionadas a traumas abertos ou fechados, com risco de complicações. Relatamos três casos semelhantes, decorrentes de crises de tosse, destacando o aspecto das alterações anatômicas nos exames de imagem obtidos em cada situação (radiografia, ultrassonografia, TC e ressonância magnética).

Descritores: Hérnia diafragmática; Radiografia; Ultrassonografia; Tomografia; Imagem por ressonância magnética.

\section{Introduction}

The occurrence of herniation of abdominal contents through the diaphragm and intercostal muscles is an uncommon phenomenon, which can be related to blunt or penetrating trauma. ${ }^{(1-4)}$ The protective cough reflex has been sporadically associated with the genesis of this entity. ${ }^{(2,5-7)}$ Failing to recognize transdiaphragmatic intercostal hernia can be potentially fatal, because of possible complications, such as strangulation. ${ }^{\left({ }^{8}\right)}$

We report the cases of three patients who developed cough-induced herniation of intestinal loops through the diaphragm and intercostal space, associated with rib fracture, describing the radiographic, ultrasonographic, $\mathrm{CT}$, and magnetic resonance findings obtained in the cases.

\section{Case reports}

\section{Case 1}

A 53-year old man presented to an outpatient clinic reporting bulging of the right inferolateral region of the chest, as well as postprandial gastric fullness and "strange" noises in the region. The patient associated the onset of the condition (more than 1 year prior) with a violent attack of coughing, followed by severe, persistent pain in the right thoracoabdominal junction, worsened by exertion. He reported that, at the time, that episode had been diagnosed as "pneumonia at the right lung base". Subsequently, an area of ecchymosis was noted along the right lateral thorax and abdomen. The pain and the hematoma resolved over weeks, whereas the progressive bulging of the region,

*Study carried out at the Hospital lsraelita Albert Einstein, São Paulo, Brazil.

Correspondence to: Ana Carolina Sandoval Macedo. Avenida Albert Einstein, 627, 4 andar, Bloco D, Morumbi, CEP 05652-900, São Paulo, SP, Brasil.

Tel. 5511 2152-2452.Fax: 5511 2152-2452.E-mail: ana.smacedo@einstein.br Financial support: None.

Submitted: 8 October 2012. Accepted, after review: 7 December 2012. 
which worsened with the patient in the orthostatic position, persisted. Physical examination revealed that his abdomen was globular, flaccid, and painless on palpation, and that there was irreducible bulging of the right eighth intercostal space, which became more evident during a Valsalva maneuver. There was an abnormal distance between the ribs of the aforementioned intercostal space, with signs of a previous separation of the costochondral junction. A CT scan of the chest revealed fractures of the anterior portion of the eighth rib, widening of the eighth intercostal space, and diaphragmatic discontinuity, through which loops of small intestine, as well as part of the colon and omentum, protruded into and occupied the subcutaneous tissue of the chest wall. In view of the diagnosis of transdiaphragmatic intercostal hernia, the patient underwent surgery via a right thoracotomy. The hernial sac was identified, the abdominal viscera were returned to the abdominal cavity, the hernial orifice was closed with a double prolene mesh and several interrupted sutures, and the pleural cavity was drained. In closing the thoracotomy, the widened intercostal space was reduced with the use of reinforcement with the same type of mesh, which was fixed to the lower and upper ribs. The patient had a favorable postoperative course, being discharged from hospital on the sixth day, with no evidence of immediate complications (Figure 1).

\section{Case 2}

A 71-year-old man reported a 2-year history of bulging of the right thoracoabdominal region, the onset of which occurred after an attack of coughing, associated with severe, stabbing pain in that region, worsened by coughing and relieved with painkillers. In addition, an area of ecchymosis was noted along the lateral region of the abdomen after the onset of pain. The pain gradually resolved, and there was progressive bulging of the region. Physical examination revealed that his abdomen was globular, flaccid, and painless on palpation, and that there was reducible bulging of the eighth intercostal space, which became more evident during a Valsalva maneuver. There was a $4-5 \mathrm{~cm}$ distance between the ribs of the aforementioned intercostal space, with signs of a previous separation of the costochondral junction. A chest radiograph showed fractures of the anterior portion of the eighth rib and widening of the eighth intercostal space. Ultrasound examination of the region with a high-frequency transducer demonstrated a formation with echotexture similar to that of the liver, protruding through the aforementioned intercostal space into the subcutaneous region. A noncontrast CT scan confirmed that it was transdiaphragmatic intercostal herniation of part
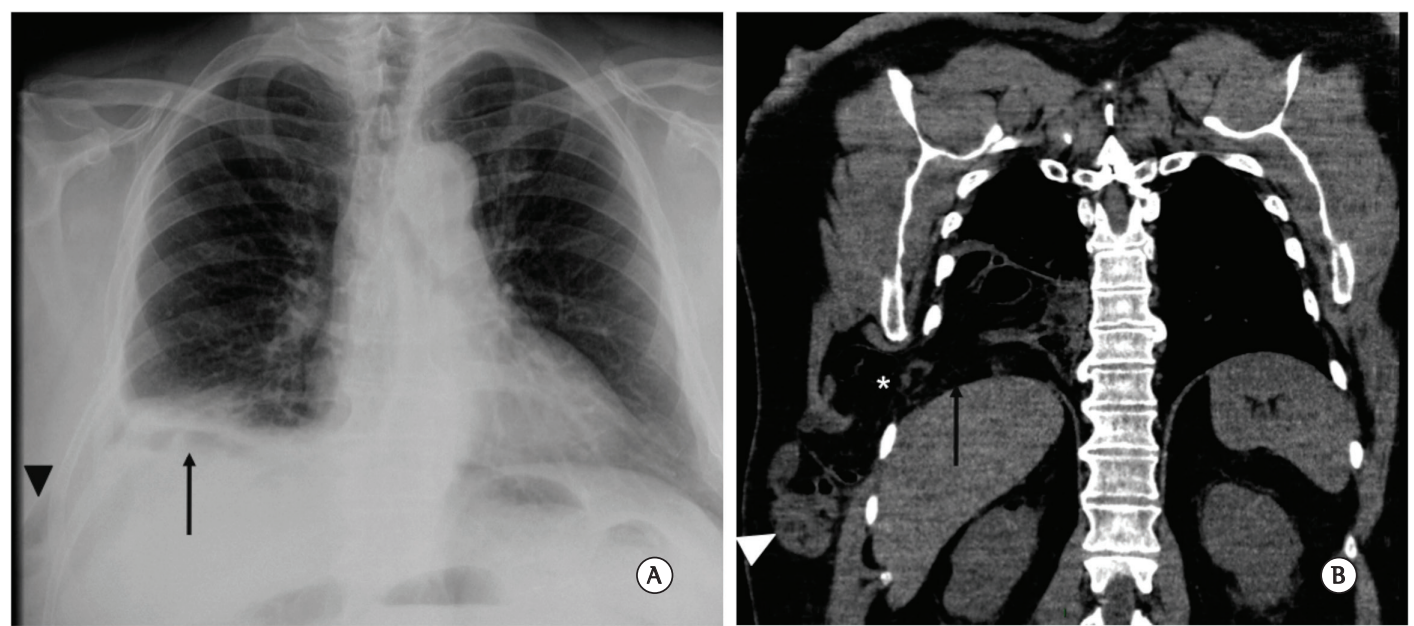

Figure 1 - $\ln$ A, posteroanterior chest radiograph. The arrow demonstrates opacification at the base of the right hemithorax, interspersed with some gas images. The arrowhead indicates soft tissue swelling in the periphery of the right lateral chest wall, with some gas images similar to those observed at the base of the right hemithorax. In B, coronal reconstruction of a noncontrast CT scan of the chest showing herniation of abdominal content into the base of the right hemithorax through the diaphragm (arrow), as well as through the eighth intercostal space (asterisk), headed toward the subcutaneous tissue of the chest wall. Note the presence of thin loops in the subcutaneous tissue of the chest wall (arrowhead). 


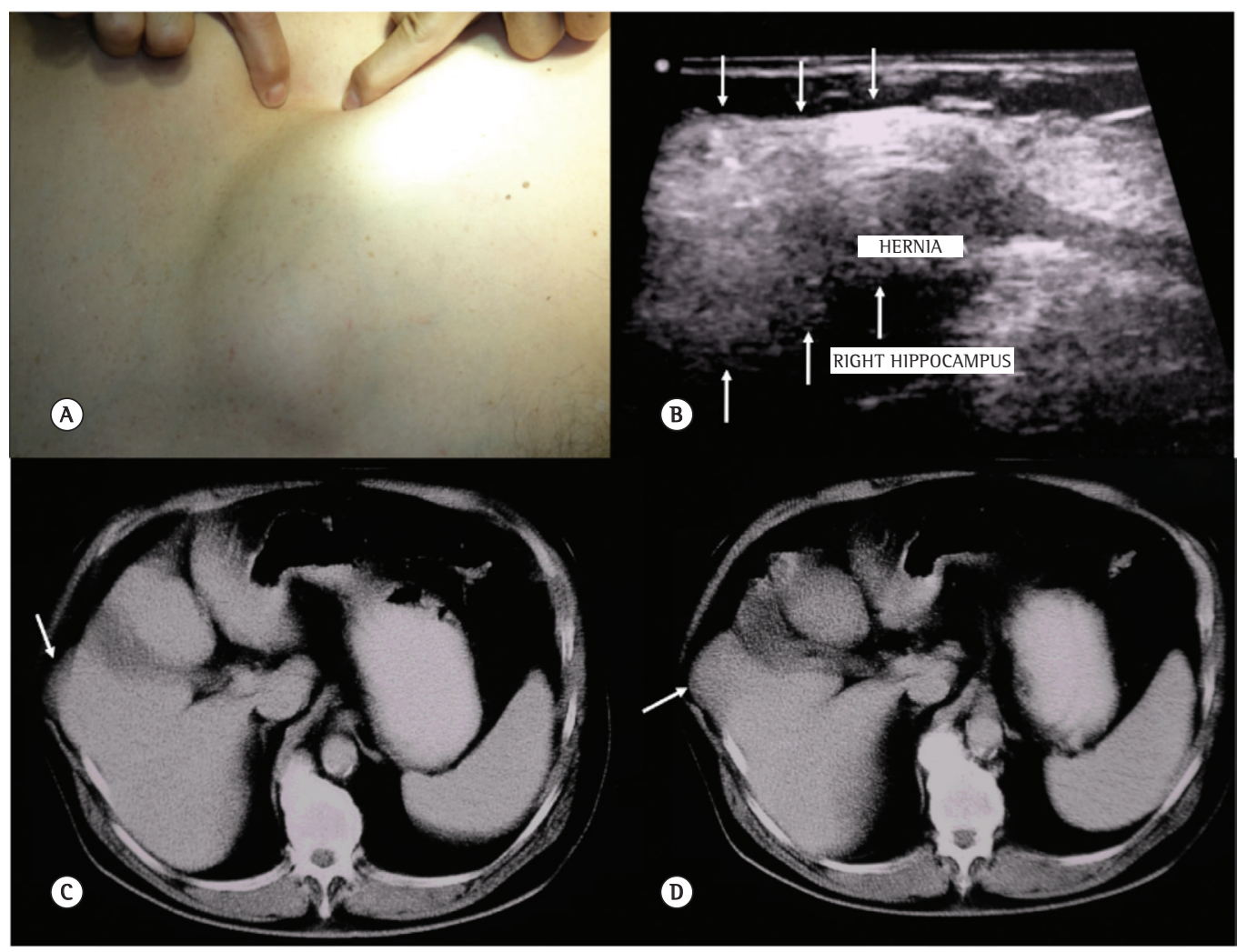

Figure 2 - In A, photograph showing visible bulging of the region of the right eighth intercostal space, on examination of the chest wall. In $\mathrm{B}$, surface ultrasound examination of the region demonstrating a formation with echotexture similar to that of the liver, extending beyond the musculoskeletal boundaries of the chest wall and occupying the subcutaneous region (arrows). In C and D, axial CT slices of the upper abdomen demonstrating that part of hepatic segment $\mathrm{V}$ protruded through the area of muscle discontinuity, headed toward the adjacent subcutaneous region.

of hepatic segment V. The patient underwent surgical correction via a thoracotomy, and a diaphragmatic tear was identified near the chest wall. The diaphragm was reattached to the ribs, and the rib borders were approximated with a nonabsorbable suture (Figure 2).

\section{Case 3}

A 64-year-old male former smoker (55 packyears) who was being noncompliant with COPD treatment had an episode of uncontrollable coughing that caused acute, intense pain in the right hypochondrium, followed by the onset of ecchymosis, which was visible locally. He sought medical care and received symptomatic treatment only. He experienced progressive worsening of dyspnea, and, after 4 months, dyspnea on minimal exertion became evident. At that point, the patient sought a pulmonologist, who requested a chest radiograph, which revealed opacification of the right lung base and soft tissue swelling in the right inferolateral chest wall, interspersed with gas images. The patient was tachypneic (RR, 26 breaths/min) and had decreased breath sounds at the right base. In addition, an area of weakness of the ipsilateral chest wall was noted on palpation. A CT scan of the chest demonstrated herniation of abdominal adipose tissue into the right lung base and chest wall, through discontinuities in the diaphragmatic and intercostal muscles, associated with the presence of fractures of the last ribs on the right. Magnetic resonance confirmed the extensive herniation of the abdominal content through the muscle discontinuities. The patient subsequently underwent surgical correction of changes, with the presence of intestinal loops in the subcutaneous and intrathoracic regions being confirmed after a thoracotomy. On examination of the cavity, it was of 
note that there was a rent in the anterolateral portion of the diaphragm, through which the abdominal content protruded. After the structures were returned to their site of origin, the diaphragmatic defect was sutured, and reinforcement with a polypropylene mesh was performed. The patient had a favorable postoperative course, being discharged on the sixth day, with decreased dyspnea (Figure 3).

\section{Discussion}

Intercostal hernia is mostly caused by blunt or penetrating trauma to the thoracoabdominal region. (9) The occurrence of "spontaneous" diaphragmatic rupture with herniation of abdominal structures is uncommon. ${ }^{(2,10)}$ Intercostal hernia is mostly associated with factors leading to a sudden increase in abdominal pressure, such as weight lifting, dancing, labor, vomiting, and cough, the last being the most common cause. ${ }^{(10,11)}$

Transdiaphragmatic intercostal hernia can be acute or can progress over time (even years) to be diagnosed. ${ }^{(9)}$ It occurs because of rupture of the diaphragm and intercostal muscles, which is mostly associated with rib fracture. There are two sites that are most susceptible: anteriorly, the costochondral junction to the sternum, because of lack of external intercostal muscles; and, posteriorly, the rib vertebral angle, because of lack of internal intercostal muscles. ${ }^{(9)}$

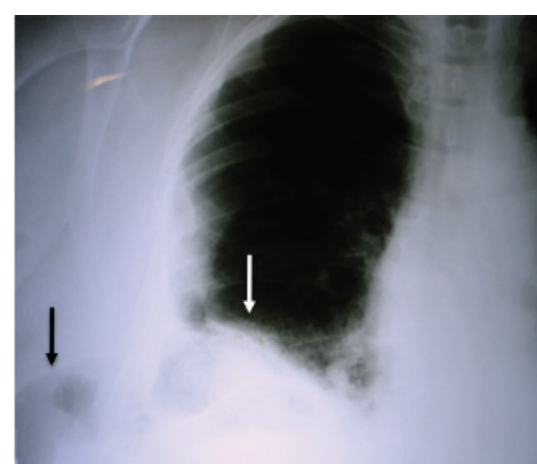

(A)

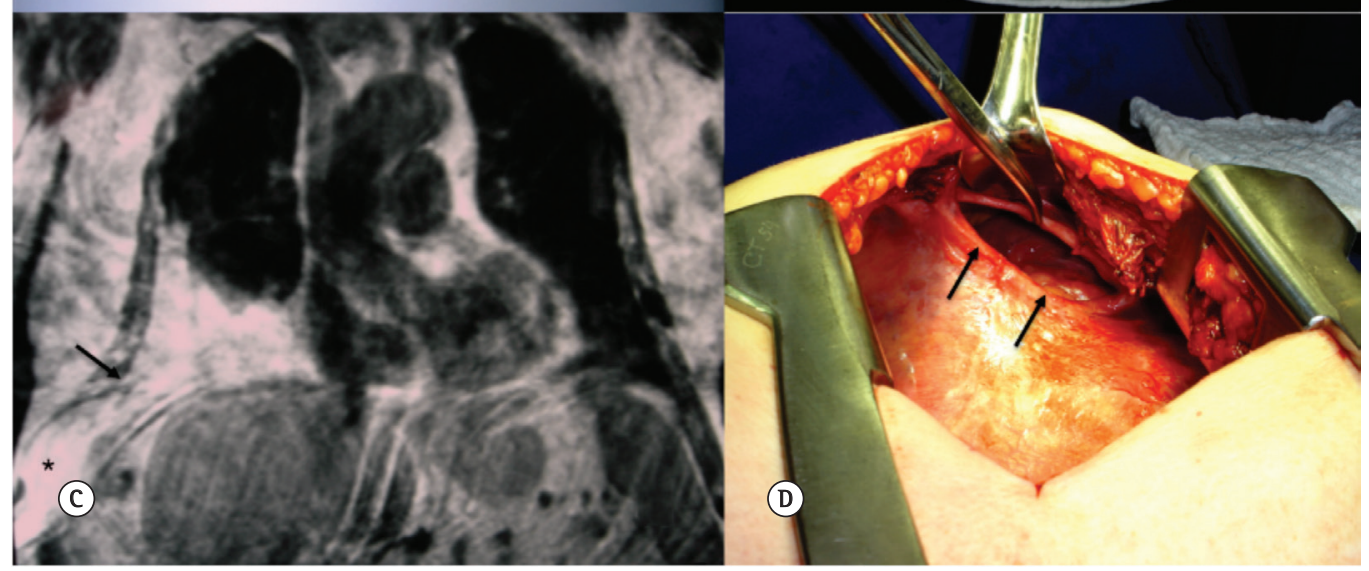

Figure 3 - In A, posteroanterior chest radiograph demonstrating opacification at the base of the right hemithorax, superiorly displacing the lung parenchyma (white arrow). Note the widening of the eighth intercostal space and the presence of a structure with gas density, similar to an intestinal loop, occupying the soft tissues of the adjacent chest wall (black arrow). In B, axial CT image of the chest, where it is possible to observe the passage of epiploic fat into the base of the right hemithorax and subcutaneous tissue of the chest wall (asterisk). Note the presence of a fracture of the ninth rib (white arrow). In C, coronal T1-weighted non-fat-saturated magnetic resonance image demonstrating the presence of a large amount of abdominal fat herniated into the base of the right hemithorax. Note the discontinuity of the intercostal muscles (black arrow), through which the content herniates into the subcutaneous tissue of the chest wall. In D, photograph showing the main surgical finding: a rent in the anterolateral portion of the diaphragm. 
When intercostal hernia is related to attacks of uncontrollable coughing, it is mostly associated with rib fracture. The cough mechanism involves the opposing forces of the abdominal muscles and chest wall acting on the ribs, leading to fractures and muscle tears. ${ }^{(1,2,9)}$

It presents clinically as reducible bulging of the affected intercostal space. ${ }^{(9)}$ Our three patients reported the development of ecchymosis in the thoracoabdominal region, with progressive bulging. Chest radiograph can demonstrate opacification at the affected lung base, with gas images suggestive of intestinal loops, which extend into the chest wall through the widened intercostal space. The hernial content can be more accurately evaluated by ultrasound, especially when it comes to solid organs, such as the liver. However, this method is not always able to define the hernial content, particularly when the interposition of air-distended loops obstructs the acoustic window, with CT being superior in these cases. ${ }^{(9)}$ To the best of our knowledge, this is the first case report to demonstrate the aspect of an transdiaphragmatic intercostal hernia as seen by magnetic resonance.

Treatment in these cases is surgery, which involves reducing the hernia, suturing the diaphragmatic defect, and approximating the ribs. Because of the possibility of recurrence, reinforcement with a prosthetic mesh can be performed.

\section{References}

1. Unlu E, Temizoz 0, Cagli B. Acquired spontaneous intercostal abdominal hernia: case report and a comprehensive review of the world literature. Australas
Radiol. 2007;51(2):163-7. http://dx.doi.org/10.1111/j.14401673.2006.01661.x PMid:17419863

2. Daniel R, Naidu B, Khalil-Marzouk J. Cough-induced rib fracture and diaphragmatic rupture resulting in simultaneous abdominal visceral herniation into the left hemithorax and subcutaneously. Eur J Cardiothorac Surg. 2008;34(4):914-5. http://dx.doi.org/10.1016/j. ejcts.2008.06.048 PMid:18715797

3. Fiane AE, Nordstrand K. Intercostal pulmonary hernia after blunt thoracic injury. Eur J Surg. 1993;159(67):379-81. PMid:8104503

4. Llarges CM, Roesler LV, Gomes AF, Barreto CE. Hérnia diafragmática encarcerada com boa evolução após duas intervenções cirúrgicas: relato de caso. J Pneumol. 1998;24(1):43-6.

5. George L, Rehman SU, Khan FA. Diaphragmatic rupture: A complication of violent cough. Chest. 2000;117(4):1200-1. http://dx.doi.org/10.1378/chest.117.4.1200 PMid:10767262

6. Connery A, Mutvalli E. Cough-induced abdominal intercostal hernia. JRSM Short Rep. 2010;1(3):23. http:// dx.doi.org/10.1258/shorts.2010.010029 PMid:21103115 PMCid:PMC2984347

7. Hillenbrand A, Henne-Bruns D, Wurl P. Cough induced rib fracture, rupture of the diaphragm and abdominal herniation. World J Emerg Surg. 2006;1:34. http:// dx.doi.org/10.1186/1749-7922-1-34 PMid:17125506 PMCid:PMC1675993

8. Bendinelli C, Martin A, Nebauer SD, Balogh ZJ. Strangulated intercostal liver herniation subsequent to blunt trauma. First report with review of the world literature. World J Emerg Surg. 2012;7(1):23. http://dx.doi.org/10.1186/17497922-7-23 PMid:22800293 PMCid:PMC3441203

9. Cole FH Jr., Miller MP, Jones CV. Transdiaphragmatic intercostal hernia. Ann Thorac Surg. 1986;41(5):565-6. http://dx.doi.org/10.1016/S0003-4975(10)63045-7

10. Croce EJ, Mehta VA. Intercostal pleuroperitoneal hernia. J Thorac Cardiovasc Surg. 1979;77(6):856-7. PMid:374885

11. Nakanishi H, lwasaki S, Ohkawa Y, Nakazawa H, Mineta H. Diaphragmatic rupture due to violent cough during tracheostomy. Auris Nasus Larynx. 2010;37(1):121-4. http:// dx.doi.org/10.1016/j.anl.2009.01.015 PMid:19423248

\section{About the authors}

Ana Carolina Sandoval Macedo

Attending Physician. Hospital lsraelita Albert Einstein, São Paulo, Brazil.

Fernando Uliana Kay

Attending Physician. Hospital lsraelita Albert Einstein, São Paulo, Brazil.

\section{Ricardo Mingarini Terra}

Collaborating Professor. Department of Thoracic Surgery, University of São Paulo School of Medicine, São Paulo, Brazil.

\section{José Ribas Milanez de Campos}

Tenured Professor. Department of Thoracic Surgery, University of São Paulo School of Medicine, São Paulo, Brazil.

\section{André Galante Alencar Aranha}

Coordinator. Department of Thoracic Surgery, Fundação Lusiada School of Medicine; and Assistant Professor. Respiratory Tract Department, Methodist University at Santos School of Medicine, Santos, Brazil.

Marcelo Buarque de Gusmão Funari

Medical Manager. Imaging Department, Hospital lsraelita Albert Einstein, São Paulo, Brazil. 